\title{
The ProSeal laryngeal mask airway: fibreoptic visualization of the glottic opening is associated with ease of insertion of the gastric tube
}

\author{
[Le masque laryngé ProSeal : la visualisation fibroscopique de l'ouverture \\ glottique est associée à une facilité d'insertion du tube gastrique]
}

Felice Agrò MD, Serena Antonelli MD, Rita Cataldo MD, Francesco Montecchia, Giorgio Barzoi MD, Tommasangelo Petitti MD

Purpose: To verify if correct ProSeal laryngeal mask airway (PLMA) placement may condition blind insertion of a gastric tube via the PLMA.

Methods: The PLMA was studied in 150 anesthetized patients using a size \#4 in (females) and \#5 in (males). Its position was determined by inserting a fibrescope in the airway tube. A lubricated gastric tube was inserted through the PLMA drainage tube, recording the number of attempts at insertion. The relationship between fibreoptic glottic visualization score and attempts at gastric tube insertion using the PLMA was tested statistically.

Results: Insertion success rate of the PLMA and of the gastric tube was $93.3 \%$ and $99.3 \%$, respectively. Ventilation was satisfactory in all patients, irrespective of fibreoptic score value. A significant correlation (Spearman's rank correlation, $P=0.0186$ ) was present between attempts at gastric tube insertion and fibreoptic score.

Conclusion: Partial or total visualization of the vocal cords makes the success of gastric tube insertion more probable. Considering that fibreoptic visualization of the glottic aperture is associated with ease of insertion of a gastric tube $(P<0.02)$, the authors recommend adjusting or reinserting the PLMA if difficulty during the initial positioning of the gastric tube is experienced.

Objectif : Vérifier si la mise en place correcte du masque laryngé ProSeal (MLP) peut conditionner l'insertion à l'aveugle d'un tube gastrique passant par le MLP.

Méthode : Le MLP a été testé chez 150 patients anesthésiés, en utilisant un masque no 4 chez les femmes et un no 5 chez les hommes. Sa position était déterminée en insérant un fibroscope dans le tube d'intubation. Un tube gastrique lubrifié a été inséré au travers du tube de drainage du MLP, en notant le nombre d'essais nécessaires à l'in- sertion. La relation entre le score de visualisation glottique fibroscopique et le nombre d'essais d'insertion du tube gastrique à l'aide du $M L P$ a été testé statistiquement.

Résultats : Le taux de réussite d'insertion du MLP et du tube gastrique a été de 93,3\% et de 99,3\%, respectivement. La ventilation a été satisfaisante pour tous les patients, peu importe le score fibroscopique. Une corrélation significative (corrélation des rangs de Spearman, $P=0,0186$ ) était présente entre les essais d'insertion du tube gastrique et le score fibroscopique.

Conclusion : La visualisation totale ou partielle des cordes vocales augmente les probabilités de succès d'insertion d'un tube gastrique. Considérant que la visualisation fibroscopique de l'ouverture glottique est associée à une facilité d'insertion d'un tube gastrique, $(P<0,02)$, les auteurs recommandent l'ajustement et la réinsertion du MLP en cas de difficulté au premier essai de mise en place du tube gastrique.

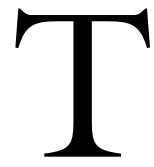

HE standard laryngeal mask airway (LMA) can be placed easily and an adequate airway can be established in the majority of patients. Its most significant limitation consists in the lack of an effective seal against pulmonary aspiration of gastric contents. ${ }^{1}$ The LMA is not recommended in non-fasting patients ${ }^{2,3}$ and in patients at risk of aspiration. ${ }^{4,5}$ In these cases the ProSeal laryngeal mask airway (PLMA), incorporating a drainage tube and a dorsal cuff could be useful. The PLMA (The Laryngeal Mask Company Ltd., Maidenhead, Berkshire, UK $)^{6-8}$ was designed by Archie Brain to ventilate the patient and simultaneously to permit

From the Department of Anaesthesia, University School of Medicine Campus Bio-Medico, Rome, Italy.

Address correspondence to: Prof. F. Agrò, Department of Anaesthesia, University School of Medicine Campus Bio- Medico, Via E.

Longoni 83 - 00155 Rome, Italy. Phone: +39-0622541522; Fax +39-0622541445; E-mail: f.agro@unicampus.it

Sources and financial support: none

Accepted for publication March 28, 2002.

Revision accepted June 10, 2002. 
access to or escape of fluids from the stomach. ${ }^{7}$ The first prototype of the PLMA, the gastric laryngeal mask airway (GLMA) has been used in our university since $1997 .^{9-12}$

The channel opening into the upper esophagus should reduce tendency for gastric insufflation when positive pressure is applied to the airway and should act as an escape route for gastric fluids in the event of unexpected reflux occurring during anesthesia. ${ }^{7}$ Keller and Brimacombe demonstrated that, in the cadaver model, the correctly placed PLMA allows fluid in the esophagus to bypass the pharynx and mouth when the drainage tube is open. ${ }^{13}$

Since the PLMA isolates the glottis from the esophagus when correctly positioned ${ }^{8}$ and the drainage tube aligns with the upper esophageal sphincter, ${ }^{14}$ we wanted to verify if an anatomic position of the PLMA (fibreoptically determined through the airway tube) would be associated with ease of gastric tube placement via the drainage tube in properly ventilated patients.

The relationship between fibreoptic glottic visualization and attempts at gastric tube insertion using the PLMA was tested in 150 patients.

\section{Methods}

Local Ethical Committee approval and patient consent for using the PLMA in minor surgical procedures (general, orthopedic and gynecologic surgeries) with maximum duration of $90 \mathrm{~min}$ were obtained. One hundred and fifty consecutive patients, ASA I-II, > 18 yr of age, fasting (eight hours), without history of gastroesophageal reflux and with a body mass index $<35$ $\mathrm{kg} \cdot \mathrm{m}^{-2}$ were studied.

Consultant anesthesiologists skilled in using the standard LMA and the GLMA performed the procedure. After pre-oxygenation for three minutes with the patient breathing spontaneously, anesthesia was induced with propofol $3 \mathrm{mg} \cdot \mathrm{kg}^{-1}$, fentanyl $3 \gamma \cdot \mathrm{kg}^{-1}$ and vecuronium $0.1 \mathrm{mg} \cdot \mathrm{kg}^{-1}$. The PLMA size was \#4 for females and \#5 for males. Standard (index finger) technique was used for PLMA positioning. At T0 (placement phase) the PLMA was inserted and the number of attempts was recorded (maximum two). The cuff of the device was then inflated at a pressure of $60 \mathrm{~cm} \mathrm{H}_{2} \mathrm{O}$ using a calibrated manometer; ${ }^{7}$ presence of leaks was checked with manual ventilation by applying a peak airway pressure of $30 \mathrm{~cm} \mathrm{H}_{2} \mathrm{O} ;{ }^{7}$ possible adjunctive maneuvres (reinsertion, caudal-cranial movements) were attempted if necessary. After PLMA insertion, the following scoring system was used to evaluate the ease of positioning: 1 = easy (immediate satisfactory ventilation), 2 = difficult (satisfactory ventilation after device position adjustment or reinser- tion) and 3 = impossible (ventilation not achieved). The data were recorded by an independent observer (consultant anesthesiologist). If an effective airway (defined as normal thoraco-abdominal movement and square capnographic waveform, expired tidal volume of $8 \mathrm{~mL} \cdot \mathrm{kg}^{-1}$ when applying positive pressure ventilation and peak airway pressure $<35 \mathrm{~cm} \mathrm{H}_{2} \mathrm{O}$ ) was not achieved within two attempts, tracheal intubation was to be carried out. A failed attempt was defined as PLMA removal from the mouth. At Tl, after obtaining an effective airway, fibreoptic evaluation of PLMA position through the airway tube was determined. We used a flexible intubating fibrescope with coaxial optics, which allow a frontal vision. Fibreoptic score was evaluated as: $\mathrm{l}=$ only vocal cords visible, $2=$ vocal cords plus glottic surface visible, $3=$ vocal cords plus valecullar surface visible and $4=$ for vocal cords not seen. At T2 a lubricated gastric tube (14/16 French gauge for sizes \#4 and \#5, respectively) was then inserted blindly through the drainage tube, recording the number of attempts required (one or two) or failure. The gastric tube was lubricated and passed through the PLMA drainage tube prior to PLMA insertion, to test easiness of insertion and also to lubricate the PLMA drainage tube. Its correct position was determined by aspiration with a syringe; gastric aspirate confirmed a correct position in the stomach. Using "STATA ${ }^{\circ}$ " statistical software (Stata Corporation, http://www.stata.com/), Spearman's rank correlation method was used to test the relationship between fibreoptic score values and the number of attempts at gastric tube insertion. Values of $P<$ 0.05 were considered significant.

\section{Results}

The female/male ratio was $92 / 58$. Mean age, height and weight were $50.1 \mathrm{yr}$ (S.D. 14.6), $166.3 \mathrm{~cm}$ (S.D. $6.9)$ and $69.5 \mathrm{~kg}$ (S.D. 11.5) respectively. PLMA insertion success rate was $93.3 \%(140 / 150)$. In $78.6 \%$ of patients $(110 / 140)$ an adequate ventilation was achieved easily. In $21.4 \%$ of patients $(30 / 140)$, it was necessary to move the PLMA caudally or cranially (25 cases, $83.3 \%$ ) or to reinsert it (five cases, $16.7 \%$; Table I). In $6.7 \%$ of patients $(10 / 150)$, ventilation was not possible and tracheal intubation was performed. Fibreoptic score was 1 (only vocal cords visible) in seven patients (5\%), 2 (vocal cords plus glottic surface visible) in 37 patients $(26.4 \%), 3$ (vocal cords plus valecullar surface visible) in 89 patients $(63.6 \%)$ and 4 (vocal cords not seen) in seven patients (5\%; Table II). After adjunctive maneuvres to obtain an effective airway, ventilation was satisfactory in all patients, irrespective of fibreoptic score value. 
TABLE I Frequency of effective airway after PLMA insertion

\begin{tabular}{llll}
\hline & $\begin{array}{l}\text { Number of } \\
\text { patients }\end{array}$ & Percentage & $\begin{array}{l}\text { Cumulative } \\
\text { frequency }\end{array}$ \\
\hline Impossible & 10 & $6.7 \%$ & $6.7 \%$ \\
Difficult & 30 & $20 \%$ & $26.7 \%$ \\
Easy & 110 & $73.3 \%$ & $100 \%$ \\
Total & 150 & $100 \%$ & \\
\hline
\end{tabular}

TABLE II Fibreoptic score

\begin{tabular}{lll}
\hline Fibreoptic score & Number of patients & Percentage \\
\hline 1 & 7 & $5 \%$ \\
2 & 37 & $26.4 \%$ \\
3 & 89 & $63.6 \%$ \\
4 & 7 & $5 \%$ \\
Total & 140 & $100 \%$ \\
\hline
\end{tabular}

The fibreoptic score is evaluated on a 1 to 4 scale $(1=$ only vocal cords visible, 2 = vocal cords plus glottic surface visible, $3=$ vocal cords plus valecullar surface visible, and $4=$ vocal cords not seen).

TABLE III Ease of insertion of gastric tube according to fibreoptic score

\begin{tabular}{lllll}
\hline Fibreoptic score & One attempt & Two attempts & Failure & Total \\
\hline 1 & 7 & - & - & 7 \\
2 & 36 & 1 & - & 37 \\
3 & 79 & 10 & - & 89 \\
4 & 5 & 1 & 1 & 7 \\
Total & 127 & 12 & 1 & 140 \\
\hline
\end{tabular}

Fibreoptic score is evaluated on a 1 to 4 scale $(1=$ only vocal cords visible, $2=$ vocal cords plus glottic surface visible, $3=$ vocal cords plus valecullar surface visible and $4=$ vocal cords not seen).

In $90.7 \%$ of patients $(127 / 140)$ gastric tube insertion was successful at the first attempt, while in $8.6 \%$ of cases $(12 / 140)$ a second attempt was necessary. In $0.7 \%$ of patients $(1 / 140)$ gastric tube insertion failed. Gastric tube insertion at the first attempt occurred in $5 / 7$ patients with a fibreoptic score of $4(71.4 \%)$, in $79 / 89$ patients with a fibreoptic score of $3(88.8 \%)$, in $36 / 37$ patients with a fibreoptic score of $2(97.3 \%)$ and in $7 / 7$ patients with a fibreoptic score of $\mathrm{l}(100 \%$; Table III; Figure).

A significant correlation $(P=0.0186)$ between attempts at gastric tube insertion and fibreoptic score was present.

\section{Discussion}

An adequate ventilation was obtained in $93.3 \%$ of patients. In $21.4 \%$ of patients, adjunctive maneuvres or reinsertion of the PLMA were needed, probably

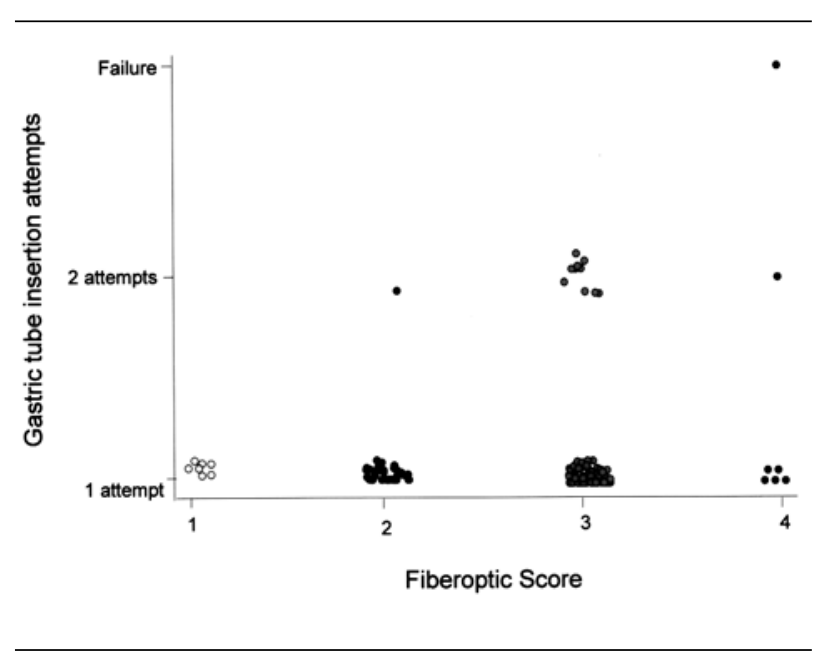

FIGURE Attempts at gastric tube insertion and fibreoptic score. Fibreoptic score used: $1=$ only vocal cords visible, $2=$ vocal cords plus glottic surface visible, $3=$ vocal cords plus valecullar surface visible, and $4=$ vocal cords not seen.

because the large dorsal cuff of the PLMA did not adjust immediately to the anatomy of the pharynx of the patients.

Although the fibreoptic score was 1 (only vocal cords visible) in only $5 \%$ of patients in whom the PLMA was inserted, ventilation was excellent in all patients irrespective of fibreoptic score value.

We feel that partial or total visualization of the vocal cords makes the success of gastric tube insertion more probable, in light of the correlation between insertion success at the first attempt and fibreoptic score. Conversely, the successful and easy passage of a gastric tube should be indicative of the correct positioning of the PLMA.

Passage of a lubricated gastric tube through the gastric conduit and aspiration of gastric juice is an essential test for determination of correct placement and, in effect, if difficult positioning of the gastric tube is experienced with an effective airway, we recommend adjusting or reinserting the PLMA.

In conclusion, considering that the partial or total visualization of the glottic aperture is associated with ease of insertion of a gastric tube, the authors recommend adjusting or reinserting the PLMA if difficulty during the initial positioning of the gastric tube is experienced. In our opinion there is no need to evaluate the fibreoptic visualization of the vocal cords in every patient in which the PLMA is used, but it is important to know that when the PLMA is well positioned, gastric tube insertion is easy and proper clinical performance of the device is ensured. 


\section{References}

1 Brimacombe JR, Berry A. The incidence of aspiration associated with the laryngeal mask airway: a metaanalysis of published literature. J Clin Anesth 1995; 7 : 297-305.

2 Goresky GV, Maltby JR. Fasting guidelines for elective surgical patients (Editorial). Can J Anaesth 1990; 37: 493-5.

3 Kallar SK, Everett LL. Potential risks and preventive measures for pulmonary aspiration: new concepts in preoperative fasting guidelines. Anesth Analg 1993; 77: 171-82.

4 Nanji GM, Maltby JR. Vomiting and aspiration pneumonitis with the laryngeal mask airway. Can J Anaesth 1992; 39: 69-70.

5 Fletcher JE, Kopp VJ, Heard CMB. The LMA ${ }^{\mathrm{TM}}$ and gastro-oesophageal reflux during spontaneous and controlled ventilation (Letter). Paediatr Anaesth 2001; 11 : 375-8.

6 Agrò $F$, Antonelli S, Mattei A. The proseal LMA: preliminary data (Letter). Br J Anaesth 2001; 86: 601-2.

7 Brain AIJ, Verghese C, Strube PJ. The LMA 'ProSeal' a laryngeal mask with an oesophageal vent. $\mathrm{Br} \mathrm{J}$ Anaesth 2000; 84: 650-4.

8 Brimacombe J, Keller C. The ProSeal laryngeal mask airway. A randomized, crossover study with the standard laryngeal mask airway in paralyzed, anesthetized patients. Anesthesiology 2000; 93: 104-9.

9 Agrò F, Brain A, Gabbrielli A, et al. Prevention of tracheal aspiration in a patient with a high risk of regurgitation using a new double-lumen gastric laryngeal mask airway. Gastrointest Endosc 1997; 46: 257-8.

10 Agrò F, Brimacombe J, Brain AIJ, Carassiti M, Cataldo $R$. Awake use of a new laryngeal mask prototype in a non-fasted patient requiring urgent peripheral vascular surgery. Resuscitation 1999; 40: 187-9.

11 Agrò F, Brimacombe J, Keller C, Petruzziello L, Barzoi $G$. Gastroscopy in awake and anaesthetized patients using a modified laryngel mask (Letter). Eur J Anaesthesiol 2000; 17: 652-3.

12 Agrò F, Brimacombe J, Cataldo R, Carassiti M, Barzoi $G$, Petruzziello L. A modified laryngeal mask in the endoscopic management of an esophageal tumor. Surg Endosc 2001; 15: 323 (abstract).

13 Keller C, Brimacombe J, Kleinsasser A, Loeckinger A. Does the ProSeal laryngeal mask airway prevent aspiration of regurgitated fluid? Anesth Analg 2000; 91: 1017-20.

14 Brimacombe J, Keller C, Fullekrug B, et al. A multicenter study comparing the ProSeal ${ }^{\mathrm{TM}}$ and Classic ${ }^{\mathrm{TM}}$ laryngeal mask airway in anesthetized, nonparalyzed patients. Anesthesiology 2002; 96: 289-95. 